\title{
Fabrication and Test of LARP Technological Quadrupole Models of TQC Series
}

Rodger C. Bossert, Giorgio Ambrosio, Nikolai Andreev, Emanuela Barzi, Guram Chlachidze, Sandor Feher, Vladimir S. Kashikhin, Vadim V. Kashikhin, Michael Lamm, Alfred Nobrega, Igor Novitski, Darryl Orris, Michael Tartaglia, Alexander V. Zlobin, Shlomo Caspi, Daniel R. Dietderich, Paolo Ferracin, A. R. Hafalia, GianLuca Sabbi, Arup Ghosh, and Peter Wanderer

\begin{abstract}
In support of the development of a large-aperture Nb3Sn superconducting quadrupole for the Large Hadron Collider (LHC) luminosity upgrade, several two-layer technological quadrupole models of TQC series with $90 \mathrm{~mm}$ aperture and collar-based mechanical structure have been developed at Fermilab in collaboration with LBNL. This paper summarizes the results of fabrication and test of TQC02a, the second TQC model based on RRP Nb3Sn strand, and TQC02b, built with both MJR and RRP strand. The test results presented include magnet strain and quench performance during training, as well as quench studies of current ramp rate and temperature dependence from $1.9 \mathrm{~K}$ to $4.5 \mathrm{~K}$.
\end{abstract}

Index Terms-Collars, LARP, LHC, Nb3Sn, quadrupole magnet, quench.

\section{INTRODUCTION}

H IGH gradient $\mathrm{Nb} 3 \mathrm{Sn}$ quadrupole models are being built at Fermilab and LBNL in an attempt to establish a design for an eventual luminosity upgrade at the LHC, within the framework of the US LHC Accelerator Research Program (LARP) [1]. A structure with aluminum shell (TQS) is being developed at LBNL [2]- [5] while a collar-based design with stainless steel shell (TQC) is being explored at Fermilab [6]- [8]. Five TQC models have been built and tested to date. This paper provides a brief overview of the first three models and describes in detail the fabrication experience and test results of the two most recent ones. Comparisons are made between all the models in the series.

Manuseript received August 21, 2008. First published June 05, 2009; current version published July 15,2009 . This work was supported in part by the US Department of Energy.

R. C. Bossert, G. Ambrosio, N. Andreev, E. Barzi, G. Chlachidze, S. Feher, V. S. Kashikhin, V. V. Kashikhin, M. J. Lamm, F. Nobrega, I. Novitski, D. Orris, M. Tartaglia and A. V. Zlobin are with Fermi National Accelerator Laboratory, Batavia, IL 60510 USA (e-mail: bossert@fnal.gov; giorgioa@fral.gov; andrevefnal,gov; burzi@fnal.gov; guram@fnal.gov; fehers@fnal.gov; kash@fnal-gov; vadim@fnal.gov; lamm@fnal.gov; nobrega@fnal.gov; novitski@fnal.gov; orris@fnal.gov; tartaglia@ fnal.gov; zlobin@ fnal.gov).

S. Caspi, D. Dietderich, P. Fernucin, R. Hafalia and G. L. Sabbi are with Lawrence Berkeley National Lahoratory, Berkeley, CA 94720

USA (e-ntail: s_caspi@lbLgov; drdietderich@lbl.gov; pferracin@lbl_gov; RRHafalia@lbl.gov; GLSabbi@ibl.gov).

A. Ghosh and P. Wanderer are with Brookhaven National Laboratory, Upton, NY 11973-5000 USA (e-mail: aghosh@bul.gov; wanderer@bnl.gov).

Color versions of one or more of the figures in this paper are available online at http:/heeexplore ieee. ong.

Digital Object Identifier 10.1109/TASC. 2009.2019104

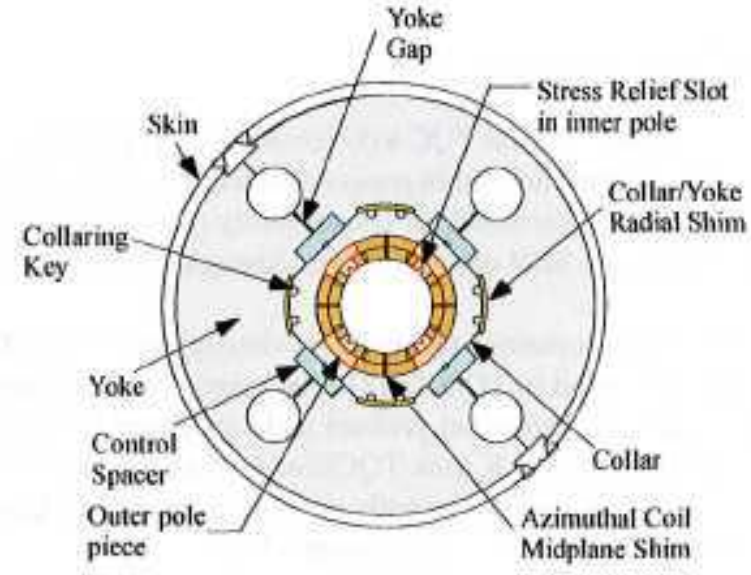

Fig. 1. TQC structure and shim system.

\section{MAGnet DESign}

\section{A. Structure}

TQC models contain a laminated collar assembly, laminated yoke and stainless steel skin as shown in Fig. L. Structural details have been previously presented [6], [8].

The TQC yoke is surrounded by a $12 \mathrm{~mm}$ thick stainless steel skin. The skin of TQC01 was welded at two positions as shown in Fig. 1. Subsequent TQC models used a skin that was identical, but bolted on for ease of assembly and so shims could be changed to adjust preload if necessary.

\section{B. Preload}

Azimuthal preload was adjusted in each magnet, by changing the values of the coil mid-plane shims based on coil size measurements after impregnation and collar-yoke shims based on collared coil diameter measurements [9]. Peak preloads after coil collaring and final assembly are read by strain gauges on the inside surfaces of the coils and the metal coil poles. They are shown for all five TQC models in Table $\mathrm{I}$. Absolute values of gauges from TQCO1a, TQCO2E and TQCO2b were not reliable after cool-down, although strain curve shapes during excitation indicated that TQCOL a showed evidence of unloading at full field, while the others did not.

\section{EXPERIENCE With Previous Models}

Experiences with TQC01a, TQCOIb and TQCO2E have been previously reported. A brief summary of their performance is included here with references to more detailed presentations. 
TABLE I

PEAK PREIOADS IN TQC MODELS (MPA)

\begin{tabular}{cccccc}
\hline $\begin{array}{c}\text { Model } \\
\text { No. }\end{array}$ & $\begin{array}{c}\text { After } \\
\text { Collaring }\end{array}$ & $\begin{array}{c}\text { After } \\
\text { Assy }\end{array}$ & $\begin{array}{c}\text { After } \\
\text { Cool- } \\
\text { down }\end{array}$ & $\begin{array}{c}\text { At Max } \\
\text { field } \\
4.5 K\end{array}$ & $\begin{array}{c}\text { At Max } \\
\text { Field } \\
1.9 \text { K }\end{array}$ \\
\hline TQC01a & 19 & 49 & N/A & N/A & N/A \\
TQC0Ib & 39 & 106 & 118 & 39 & 26 \\
TQC02E & 54 & 108 & N/A & N/A & N/A \\
TQC02a & 62 & 138 & 88 & 27 & 27 \\
TQC02b & 43 & 120 & N/A & N/A & N/A \\
\hline
\end{tabular}

\section{A. TQCOIa and TQCOIb}

TQC01a was the first TQC to be constructed [6], [7]. It contained low preload and strain gauges showed some unloading at the poles during excitation. It consequently reached only $71 \%$ of the SSL of the MJR cable at $4.5 \mathrm{~K}$, although reaching $85 \%$ at $1.9 \mathrm{~K}$.

TQCOIb [8] contained two coils previously used in TQCOIa and two coils used in TQSO1a [3]. The magnet was assembled with higher coil azimuthal preload and consequently reached higher currents at $4.5 \mathrm{~K}$ than TQC01a. At both 4.5 and $1.9 \mathrm{~K}$, TQCOIb was limited by the coils previously tested in TQSOI a at about the same level of short sample limit.

\section{B. TOCO2E}

TQC02E [8] used coils previously tested in TQS02a [4]. Collared preload was increased with respect to TQCO1b but final yoked preload was kept the same. Quench performance was approximately equivalent to TQC02a at both temperatures, reaching $87 \%$ of its short sample limit at $4.5 \mathrm{~K}$ confirming similar performance in both TQS and TQC structures when using the same coils. Subsequently, the same coils were removed and tested in two more TQS models [5], and performed at the same level, demonstrating that both the collaring and de-collaring processes can be completed without coil degradation.

\section{TQC02A CONSTRUCTION AND PERFoRMANCE}

\section{A. Design Goals and Construction}

TQC02a coils were made of RRP cable with critical current of $13873 \mathrm{~A}$ at $4.5 \mathrm{~K}$ and $15361 \mathrm{~A}$ at $1.9 \mathrm{~K}$. Two coils (17 and 19) had been previously collared and de-collared while two ( 24 and 27) had never been pressed.

The primary design goal for TQC02a was to repeat or improve the performance of TQC02E with a new set of RRP coils. A secondary goal was to increase the preload in the collared state while maintaining the same final preload as TQC02E. The preload is increased during the yoking process by locally applying pressure at the mid-planes through the collar-yoke shim, thereby bending the coils. Since the coil cross section remains round during the collaring process, increasing the collared preload with respect to the increment applied by the yoke was thought to minimize bending in the coils and distortion in the cross section. The process of increasing the collared preload with respect to the final assembled value had already

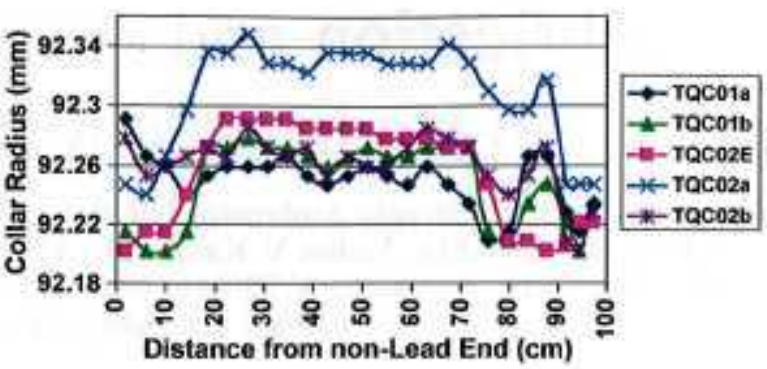

Hig. 2. Collar deflections after collaring in TQC models.

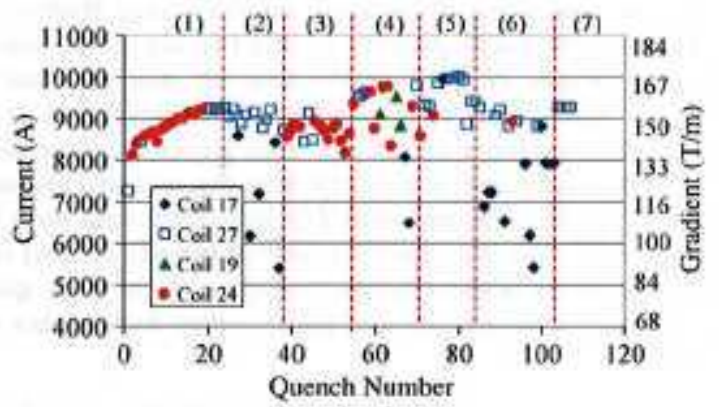

Fig. 3. TQCO2a quench history key to zones: (1) $4.5 \mathrm{~K} 20 \mathrm{~A} / \mathrm{s}$, (2) $4.5 \mathrm{~K}$ ramp rate studies, (3) $1.9 \mathrm{~K} 20 \mathrm{~N} / \mathrm{s}$, (4) $1.9 \mathrm{~K}$ nump rate studies, (5) temp dependence studies, (6) $4.5 \mathrm{~K}$ ramp rate studies, (7) $4.5 \mathrm{~K} 20 \mathrm{~A} / \mathrm{s}$.

been begun in TQCO2E, and continued in TQC02a (see the "after collaring" column in Table I).

The design goal of higher collared preload of TQC02a and similar final assembled preload was achieved, as shown in Table I. Higher collared pressures in this magnet were confirmed by collar deflection measurements shown in Fig. 2 .

An end load of approximately $14 \mathrm{kN}$ per end (support, but not significant compression) was applied, as was done in all previous TQC models.

\section{B. Quench Performance}

TQC02a was tested in the Fermilab Vertical Magnet Test Facility (VMTF) in January and February of 2008.

Magnet training was done in liquid helium at both $4.5 \mathrm{~K}$ and $1.9 \mathrm{~K}$ and is shown in Fig. 3. The first quench was at $7245 \mathrm{~A}$. in coil 24. Slow training continued in coil 24 until the quench position changed to coil 27 , at a very specific spot near the return end of layer 1, at about $9250 \mathrm{~A}$, about $67 \%$ of critical current. All subsequent quenches at $4.5 \mathrm{~K}$ remained at this precise current and position.

Training at $1.9 \mathrm{~K}$ followed a pattern similar to that in previous TQC and TQS models with RRP cable. Current at the training ramp rate of $20 \mathrm{~A} / \mathrm{s}$ did not increase from that at $4.5 \mathrm{k}$, and occurred primarily in low field areas of the outer layer. A slight increase occurred at higher ramp rates, but quenches still occurred in low field areas. It is likely that flux jump instabilitics in the RRP cable is the source of this behavior.

Reasons for the poor quench performance of TQC02a at $4.5 \mathrm{~K}$ are not precisely known at this time. Several possibilities (described below) are being evaluated. 


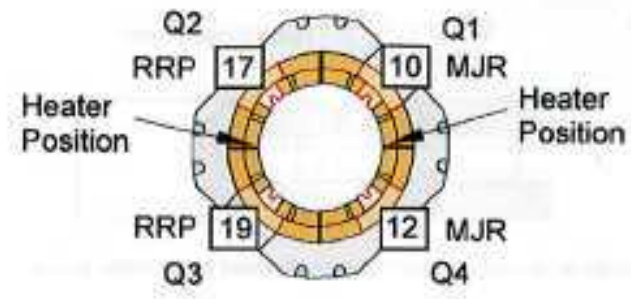

Fig. 4. TQCO2b coil and heater configuration.

One possibility is a local flaw in one or more of the coils. Almost all quenches occurred in coils 24 and 27 , and both had issues during reaction which could have limited their performance. Coil 24 was reacted together with a coil that had tin leaks, although none were evident in coil 24 . Coil 27 was reacted with a coil that had poor impregnation, although coil 27 looked fully impregnated. Also, witness samples placed with coil 27 during reaction had burst strands, although none could be directly observed on the coil. A burst strand could have caused the final quench current limit at a precise position in coil 27.

The aggressive collaring technique (using high collared preload) implemented for this magnet could also have resulted in degradation. TQC models are collared incrementally (in $80 \mathrm{~mm}$ longitudinal segments), causing a stress gradient to develop during the collaring operation between the segment being compressed and the adjacent un-pressed segment. Since the total collaring preload in TQC02a was higher than in previous models while the number of collaring steps (6) remained the same, the coils were subjected to higher incremental stresses during collaring. In addition to the high collared preload, TQCO2 a was made from two new coils and two coils that had been previously pressed. The two new coils ( 24 and 27 ) were softer than the others because they had not been pre-conditioned, and would experience more strain during this operation, making them more likely to be affected.

Finally, mechanical problems could have resulted from the internal design of the coils, as described in Section VI.

TQC02a contained the standard TQC instrumentation system. Strain gauges were placed at the bronze poles of $\mathrm{TQCO} 2 \mathrm{~b}$ as well as on the inner coil surface. Control spacers, skin and end preload bolts were instrumented. Peak preload shown by the azimuthal gauges mounted to the bronze inner poles is shown in Table I. Preload at $1.9 \mathrm{~K}$ was approximately the same as $4.5 \mathrm{~K}$, since the quench current was only marginally higher. Control spacers remained loaded during cool-down, with load decreasing during excitation, as expected. Skin stress was $150 \mathrm{MPa}$ after assembly, increased to $265 \mathrm{MPa}$ during cool-down and remained approximately constant during excitation. End load was $17 \mathrm{kN}$ after assembly, remained constant during cool-down and increased during excitation to $77 \mathrm{kN}$, slightly higher than the increase in TQCO1b.

\section{TQC02B CONSTRUCTION AND PERFORMANCE}

\section{A. Design Goals and Construction}

TQC02b had several goals. The first was to provide additional verification that successful operation could be achieved with the collaring process when returning to the lower collared preload

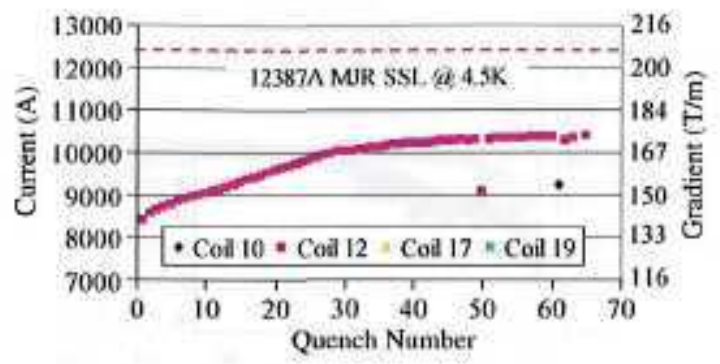

Fig. 5. TQCO2b quench performance at 4.5 K. The final 5 quenches (beginning with the quench in coil 10) were at higher ramp rates.

used in earlier magnets. Preload levels during collaring were returned to the lower levels used in TQCOIb. Another goal was to demonstrate conclusively that the erratic performance of the RRP coils at $1.9 \mathrm{~K}$ resulted from instabilities in the cable. To achieve this, two RRP coils and two MJR coils were used, configured as shown in Fig. 4. At $1.9 \mathrm{~K}$, quench protection heaters were to be used to heat the outer layer and study the instabilities in the RRP cable, as was previously done at FNAL in LM02 [10]. A third goal was to measure the temperature margin of MJR vs. RRP coils by using small 25 um thick stainless heaters at each junction between an RRP and MJR coil. This study is reported elsewhere [11].

Preload levels during collaring were returned to the lower levels used in TQCOIb (see Table I). The lower collared pressures in this magnet were confirmed by collar deflection measurements shown in Fig. 2.

\section{B. Performance}

TQC02b was tested in the Fermilab Vertical Magnet Test Facility (VMTF) in August of 2008. Test plan included quench performance and ramp rate studies at 4.5 and $1.9 \mathrm{~K}$, temperature margin studies at $4.5 \mathrm{~K}$ using the mid-plane heaters, and studies of the instabilities in the RRP coils at $1.9 \mathrm{~K}$ using the quench protection heaters to heat the outer layer.

Quench performance of $\mathrm{TQCO} 2 \mathrm{~b}$ is shown in Fig. 5. Nominal current ramp rate for training quenches was $50 \mathrm{~A} / \mathrm{s}$. The first quench was $8420 \mathrm{~A}$, at $68 \%$ of the critical current limit of the conductor. Training proceeded in a slow but linear path with all quenches in coil 12 near the gap between straight section and end pole pieces at the return end of the inner layer. The plateau was reached at $10382 \mathrm{~A}$, about $84 \%$ of the critical current limit, similar to that of TQC01b. This performance provides additional evidence that the collaring process can be completed without degrading the cable. Magnet testing at $1.9 \mathrm{~K}$ is in progress.

TQCO2b was instrumented with the same strain gauge system as TQCO2a. Coil gauges showed that preload decreased from $120 \mathrm{MPa}$ to $65 \mathrm{MPa}$ during cool down and did not unload during training at $4.5 \mathrm{~K}$. Control spacers remained loaded during cooldown, with load decreasing during excitation, as expected. Skin stress was $175 \mathrm{MPa}$ at assembly, increased to $260 \mathrm{MPa}$ during cool down and remained approximately constant during excitation, as expected. End load was $12 \mathrm{kN}$ after assembly, decreased slightly to $9 \mathrm{kN}$ during cool down and increased during excitation to $54 \mathrm{kN}$. 


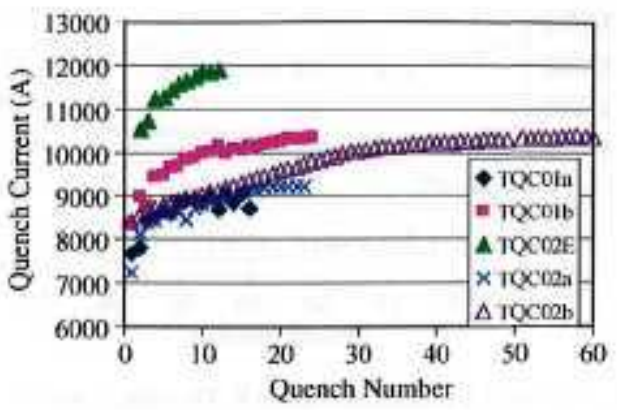

Fig. 7. Quench Performance of all TQ models at $4.5 \mathrm{~K}$. Training behavior of models with potted in parts and no pole slots show differeat training eurve than models with pole slots and outer layer parts not potted.

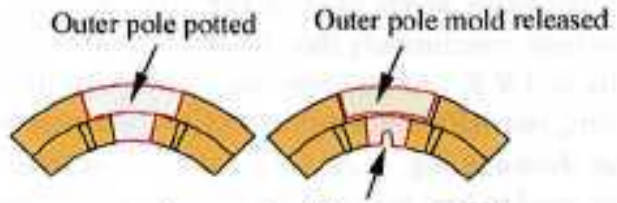

Inner pole with stress relief slot

Fig. 6. TOC coil styles.

TABLE II

COILS USED IN TQC MODER

\begin{tabular}{ccccc}
\hline Model & Q1 & Q2 & Q3 & Q4 \\
\hline TQC01 & $\mathrm{J} / \mathrm{B} / \mathrm{NP} / \mathrm{S}$ & $\mathrm{J} / \mathrm{B} / \mathrm{NP} / \mathrm{S}$ & $\mathrm{J} / \mathrm{B} / \mathrm{NP} / \mathrm{S}$ & $\mathrm{J} / \mathrm{B} / \mathrm{NP} / \mathrm{S}$ \\
$\mathrm{TQCO1b}$ & $\mathrm{J} / \mathrm{B} / \mathrm{P} / \mathrm{N}$ & $\mathrm{J} / \mathrm{B} / \mathrm{NP} / \mathrm{S}$ & $\mathrm{J} / \mathrm{B} / \mathrm{P} / \mathrm{N}$ & $\mathrm{J} / \mathrm{B} / \mathrm{NP} / \mathrm{S}$ \\
$\mathrm{TQC02E}$ & $\mathrm{R} / \mathrm{T} / \mathrm{P} / \mathrm{N}$ & $\mathrm{R} / \mathrm{T} / \mathrm{P} / \mathrm{N}$ & $\mathrm{R} / \mathrm{T} / \mathrm{P} / \mathrm{N}$ & $\mathrm{R} / \mathrm{T} / \mathrm{P} / \mathrm{N}$ \\
$\mathrm{TQC02 \textrm {a }}$ & $\mathrm{R} / \mathrm{B} / \mathrm{NP} / \mathrm{S}$ & $\mathrm{R} / \mathrm{B} / \mathrm{NP} / \mathrm{S}$ & $\mathrm{R} / \mathrm{B} / \mathrm{NP} / \mathrm{S}$ & $\mathrm{R} / \mathrm{B} / \mathrm{NP} / \mathrm{S}$ \\
$\mathrm{TQC02 \textrm {b }}$ & $\mathrm{J} / \mathrm{B} / \mathrm{NP} / \mathrm{S}$ & $\mathrm{R} / \mathrm{B} / \mathrm{NP} / \mathrm{S}$ & $\mathrm{R} / \mathrm{B} / \mathrm{NP} / \mathrm{S}$ & $\mathrm{J} / \mathrm{B} / \mathrm{NP} / \mathrm{S}$ \\
\hline
\end{tabular}

\section{EFFECTS OF COIL DESIGN}

All coils in TQC models have the same cable size and cross section. However, they are made with several different features, some of which affect the performance of the magnet.

Cable may be manufactured by either the Modified Jelly Roll (MJR) the Rod Restack Process (RRP). Pole pieces may be either Bronze or Titanium alloy. Outer poles may or may not be potted into the cross section (some are mold released during impregnation so they can be removed later), and inner poles may contain slots as shown in Fig. 6.

Table II lists the TQC models used and the coil styles used within them. Some models (TQCOIb and TQCO2b) contained more than one style. (Key: MJR $=J, R R P=R$, $\mathrm{B}=$ Bronze, $\mathrm{T}=$ Titanium, $\mathrm{P}=$ potted outer poles, $\mathrm{NP}=$ non - potted outer poles, $\mathrm{S}=$ inner coil pole slot, $\mathrm{N}=$ no pole slot).

Training behavior of all TQC models at $4.5 \mathrm{~K}$ is compared in Fig. 7. The rate of training in all coils with mold released outer poles and inner slots (TQC01a, TQC02a and TQC02b) display a distinct pattern (slow, linear increase), whereas coils with potted parts and no slots show a steeper rise and earlier plateau, even though all magnets used an identical structure.

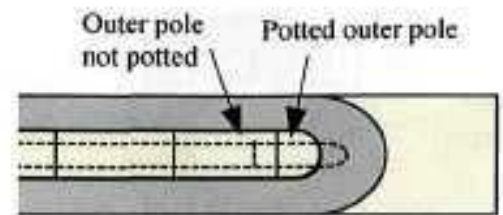

Fig. 8. Position of junction between potted and non-potted poles.

TABLE III

TQC PERFORMANCE

\begin{tabular}{ccccc}
\hline Model & $\begin{array}{c}\text { SSL (I) } \\
4.5 \mathrm{~K} / 1.9 \mathrm{~K}\end{array}$ & $\begin{array}{c}\text { Quench } \\
\text { Plateau (I) } \\
4.5 \mathrm{~K} / 1.9 \mathrm{~K}\end{array}$ & $\%$ of SSL & $\begin{array}{c}\text { Gradient } \\
(\mathrm{T} / \mathrm{m}) \\
4.5 \mathrm{~K} / 1.9 \mathrm{~K}\end{array}$ \\
\hline TQC01a & $12745 / 14082$ & $9092 / 11950$ & $71 / 85$ & $154 / 200$ \\
TQC01b & $12378 / 13679$ & $10559 / 11957$ & $85 / 87$ & $178 / 200$ \\
TQC02E & $13873 / 15361$ & $12004 / 11818$ & $87 / 77$ & $201 / 199$ \\
TQC02a & $13873 / 1536 \mathrm{I}$ & $9251 / 10009$ & $67 / 65$ & $156 / 168$ \\
TQC02b & $12378 / 13679$ & $10382 / \mathrm{TBD}$ & $84 / \mathrm{TBD}$ & $175 / 1 \mathrm{BD}$ \\
\hline
\end{tabular}

Also, pole gauges on TQC01b, which were mounted on coils without pole slots, show a slight increase in preload with cool down, while those on coils with pole slots show a decrease.

In addition, quench positions of adequately preloaded coils of the NP/S type have many quenches between the outer potted end pole section and non-potted section (see Fig. 8), while those with P/N type have quenches distributed more evenly throughout the body [12]. Although these quenches occur in the inner layer while the junction between potted and non-potted parts is in the outer layer, high stresses during collaring as well as operation may occur in this area as a result of this discontinuity. Some indication of high stress on the inner layer in this area is evident on the inside surface of coils of the NP/S type.

Future TQ as well as LQ models will incorporate potted parts without pole slots, and therefore will not be subjected to possible stresses of this type.

\section{CONCLUSION}

Five TQC models based on stainless steel collar and thick stainless steel skin support have been constructed and tested. Table III lists their current, gradient and percentage of critical current reached. TQCO1b, TQCO2E, and TQCO2b have demonstrated that the collaring process can produce magnets that perform reliably. Coils from both TQC02E and TQCO1b have been reused in other magnets with little or no performance degradation. At $1.9 \mathrm{~K}$, quench performance of all RRP coils is limited by flux jump instabilities. TQC models of the non/potted with slot coil type show slower training and sometimes low quench plateau,

Models have been shown to have preloads and stresses within the internal components that are in agreement with our simulations. Construction of four new coils based on more stable RRP 108/127 strand for the third TQ generation has begun. These coils will be tested first in the TQS structure (TQS03a), then in the TQC structure (TQC03E) in 2009. The goal of these tests is to improve magnet quench performance at both 4.5 and $1.9 \mathrm{~K}$ 


\section{REFERENCES}

II] S A Gonudigy et at, "Magnet ReDD for the US LHC Aceelerator Re sexich Program (LARP)," IEEE Trats Appised Supercandwctivity, vol 16, mo 2. pp 324-327, Juae 2006

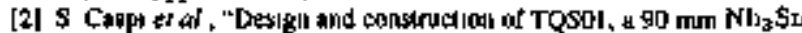
qnotrupode model for LFC Inminosily upgrade based ant a key and

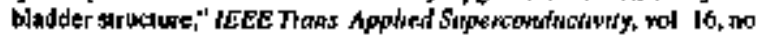
2 pp 35g-36I, June 2006

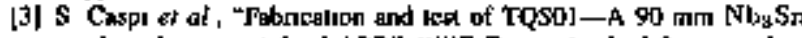

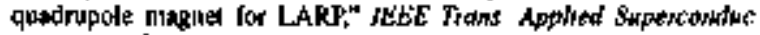
trity, wod 17, no 2. pp 1122-1]25, June 20W7

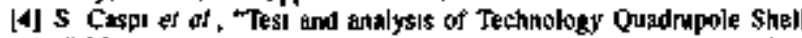
(TOS) maggnet models for LARP," JEEE Trons Apphied Supenconduc HWily, wol $\backslash 8$, a 2 2, pp IT9-183, June 2008

[5] S Cespis ef of, "Tast resulis or I.ARP Nb3Sn quadrupole magnets uging a shell based suppor moriure," presanted al the ASC 2006, SLX04, unpublikhect

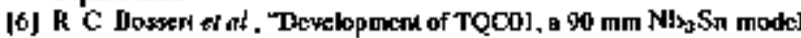
quadrupote Ior LHC Upsernide Based on SS Collar," JEEE Thars Ap phied Strpercondactruty, vol 16, to 2, PP 370-.373. June 2006
(7) 5 Ficher et of "Developmend and (ast of LARP technologenal

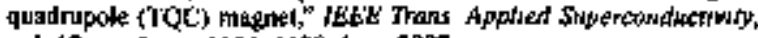
wol 17, no 2. Pp 1126-1124, Junte 2007

(8) R C Botsert et at, "Development and test of LARP tecturologecal qaidrupole models of TQC Senes," IEEE Jrans Apptred Supercondectrinty, wol 18, no 2, pp 175-178, Juace 20018

[9] D R Chuchil ef at'. "Imweghgrinon of cable inpolation and themo

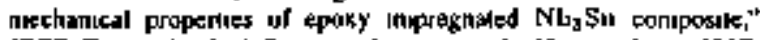
IEEE Trats Applied Strpercondinctivity, vol 10, no I, p 13IT, March 2000

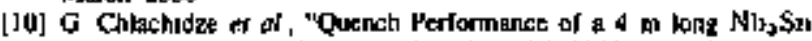
eds thets dpole conl," preseriled nl the ASC 2000, 5LX03, unpub lished

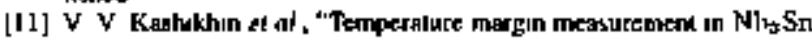
moxekeralur maynete," prasented al the ASC 2008, 3LPH10, vupub lished

[I2] R Bosser, "Quench Posilong in TQC Moviels," Fermulab Technical

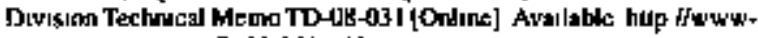

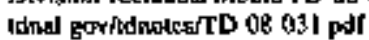

